\title{
Pre- and postoperative findings in patients with endomyocardial fibrosis ${ }^{1}$
}

\author{
O. M. HESS, M. TURINA, Å. SENNING, N. H. GOEBEL, Y. SCHOLER, \\ AND H. P. KRAYENBUEHL
}

From the Department of Internal Medicine, Surgical Clinic A, and Institute of Radiology, University of Zurich, Switzerland

SUMMARY From 1971 to 1977 endomyocardial fibrosis was diagnosed in 7 patients (6 women and 1 man) and the clinical course was followed for 36 months. Five of the 7 patients $(70 \%)$ showed partial obliteration of both ventricles; in 2 patients the fibrotic lesions were confined to the left ventricle. The main haemodynamic features were restriction to ventricular filling and atrioventricular valve regurgitation. Angiocardiographically there was a small left ventricular (LV) cavity with globular configuration and a right ventricular cavity with obliteration of the corpus and small additional cavities in the apical region. LV ejection fraction ranged from 48 to 73 per cent. Endocardial thickening of the posterior wall was found in 4 of 6 echocardiographically evaluated patients, and thickening of the right ventricular anterior wall with systolic obliteration of the cavity was detected by echocardiography in 2 patients in whom angiocardiography had shown severe fibrosis of the right ventricle.

The follow-up of 3 medically treated patients showed a stable course in 2 patients with biventricular fibrosis; one patient with LV endomyocardial fibrosis, however, died 6 years later in a severe low-output syndrome. The follow-up of the 4 surgically treated patients showed a good functional result 4 to 14 months after endocardial decortication and atrioventricular valve replacement. There was a significant decrease in LV end-diastolic pressure and a significant increase in cardiac output. LV end-diastolic volume increased in 3 patients as a result of the removal of the filling obstruction and the end-diastolic pressure-volume relation disclosed an increase in LV distensibility. One patient with incomplete decortication showed a slight decrease in postoperative distensibility.

It is concluded that (1) endomyocardial fibrosis in Switzerland is a rare disease and is observed mainly in women; (2) the clinical picture is dominated by severe congestive heart failure whereby heart size is only moderately enlarged; (3) systolic performance is normal or only slightly depressed despite severe restriction to filling and/or atrioventricular valve regurgitation; (4) partial obliteration of the right or left ventricle may be detected by echocardiography; and (5) endocardial decortication with atrioventricular valve replacement seems to be an adequate treatment with appreciable postoperative improvement in the patient's condition.

Endomyocardial fibrosis was first described in 1948 by Davies in Uganda. It is an endemic heart disease in several tropical countries, but rarely found in Europe. The essential feature of the disease is the formation of fibrous tissue on the endocardium and to a lesser extent in the myocardium. The endomyocardial fibrosis leads to partial obliteration of one or both major heart chambers and to decreased ventricular distensibility

'Supported by the Swiss National Science Foundation.

Received for publication 13 July 1977 with impairment of filling. The fibrosis is usually located at the apex of the affected ventricle and extends to the inflow tract. Involvement of the chordae tendineae is frequent and causes mitral and/or tricuspid regurgitation. Severe atrioventricular valve regurgitation and circulatory congestion resulting from the massive restriction of the ventricles are the main indications for surgery which consists of atrioventricular valve replacement and decortication of the fibrotic endocardial layers (Dubost et al., 1976).

In the present study 7 patients with endomyocardial fibrosis were evaluated by left and right 406 
Table 1 Clinical data in 7 patients with endomyocardial fibrosis

\begin{tabular}{|c|c|c|c|c|c|c|c|c|}
\hline \multirow[t]{2}{*}{ Case } & \multirow[t]{2}{*}{$\operatorname{Age}(y)$} & \multirow[t]{2}{*}{$N Y H A$} & \multicolumn{2}{|l|}{$P W C(\%)$} & \multirow[t]{2}{*}{ Follow-up (mth) } & \multirow{2}{*}{$\begin{array}{l}\text { Restudy } \\
\text { (mth post) }\end{array}$} & \multicolumn{2}{|c|}{ Prosthesis } \\
\hline & & & Before operation & After operation & & & Mitral & Tricuspid \\
\hline 1 & 39 & III & 0 & & 34 & - & - & - \\
\hline 2 & 42 & III & 0 & 48 & 72 & 14 & BS 31 & - \\
\hline 3 & 34 & III & 37 & 41 & 12 & 4 & BS 31 & HA 33 \\
\hline 4 & 32 & III & 63 & 63 & 10 & 4 & BS 31 & - \\
\hline 5 & 52 & IV & 0 & 71 & 15 & 12 & LK 22 & - \\
\hline 6 & 19 & IV & 0 & & 71 & - & - & - \\
\hline 7 & 27 & III & 81 & & 36 & - & - & - \\
\hline Mean & 35 & & 26 & 56 & 36 & 9 & & \\
\hline
\end{tabular}

NYHA, functional classification of the New York Heart Association. PWC, physical working capacity; BS 31, Björk-Shiley prosthesis no. 31 ; LK 22, Lillehei-Kaster prosthesis no. 22; HA 33, Hancock prosthesis no. 33.

heart catheterisation and their clinical course was followed for 36 months. Four patients with moderate to severe mitral regurgitation and distinct impairment of ventricular filling were treated by mitral valve replacement and endocardial decortication. They were reassessed haemodynamically 4 to 14 months after operation.

\section{Patients and methods}

From 1971 to 1977 endomyocardial fibrosis was diagnosed in 7 patients (6 women and 1 man), with an average age of 35 years (19 to 52) (Table 1). Four patients were admitted to the hospital because of severe right heart failure, 2 because of severe mitral regurgitation, and 1 patient because of biventricular heart failure. Four patients were Swiss, 1 Tibetan, 1 Yugoslavian, and 1 Italian; none had ever been in the tropics. In 5 patients the first symptoms occurred 6 months to 4 years before admission; in 2 patients with a history of rheumatic fever, however, they were present 11 and 13 years before admission. Dyspnoea on exertion, breathlessness, abdominal pain, fatigue, and nocturia were the most common complaints. According to the functional classification of the New York Heart Association (NYHA) 5 patients were in class III and 2 patients in class IV.

Physical examination showed raised venous pressure, hepatomegaly, ankle swelling, and peripheral cyanosis in 4 patients. Mitral regurgitation was diagnosed by auscultation in 7 , tricuspid regurgitation in 6 , and aortic stenosis with regurgitation in 1 patient. Blood pressure was normal in all 7 patients and in 1 case there was a tachycardia of 100 beats/min.

The chest $x$-ray film showed pulmonary congestion in 4 patients. Mild enlargement of the heart was found in all 7 patients and mean cardiothoracic ratio was $0.54(0.51$ to 0.58 ; normal $\leqslant 0.50)$. The enlargement of the heart seemed to be mainly the result of an enlarged left atrium and an enlarged right ventricle. Bizarre calcifications of the endocardium were seen in 2 patients.

The electrocardiogram disclosed no specific abnormalities. Six patients were in sinus rhythm, but one of them showed intermittent atrial flutter and another had first degree atrioventricular block. One patient was in permanent atrial fibrillation. No patient had widening of the QRS. Evidence of left atrial hypertrophy was found in 3 , and of right atrial hypertrophy in 4 patients.

Echocardiography was performed in the anteroposterior or right anterior oblique position (Echocardiovisor, Organon Teknika, 2.25 MHz). Echocardiographic examination was carried out in 6 patients.

Physical working capacity was determined on a bicycle ergometer in the upright position. Physical working capacity was defined as the work load (in watts) achieved at the submaximal pulse rate. The submaximal pulse rate adjusted for the patient's age was reached in two exercise stages of 5 minutes duration. The individual physical working capacity was given as a percentage of the normal value obtained from a nomogram. This nomogram depends on the patient's age, sex, and height.

Blood counts showed no significant eosinophilia (0 to $9 \%$ ), to suggest Löffler's (1936) endocarditis, except in case 3 three years after the onset $(46 \%)$.

Immunological tests were performed in 5 out of the 7 patients; 4 patients had antibodies against heart muscle, with a titre ranging from $1: 20$ to $1: 80$ (normal range $<1: 2$ ). Warm-reactive autoantibodies of the IgG-type were detected in one case (case 5) and were responsible for a compensated autoimmune haemolytic anaemia.

Carcinoid syndrome was excluded in 5 of the 7 patients by a normal 24-hour urinary excretion of 5-hydroxyindole-acetic acid.

All 7 patients were on digitalis and on high doses of diuretics; anticoagulants were given in 4 patients. 


\section{CARDIAC CATHETERISATION}

Right and left heart catheterisation was performed in all 7 patients. Pressure measurements were carried out by fluid-filled catheters and recording was made on an oscillograph 'Electronics for Medicine' DR/16. Premedication consisted of $10 \mathrm{mg}$ chlordiazepoxide or $5 \mathrm{mg}$ diazepam given orally 1 hour before catheterisation. Mitral regurgitation was assessed quantitatively in 4 patients by thermodilution and in one patient by dye dilution. Tricuspid regurgitation was assessed qualitatively in 4 patients by ascorbic acid. Cardiac output was estimated by the Fick principle. Left ventricular (LV) cineangiocardiography was carried out in the right and left anterior oblique position, according to our standard technique (Krayenbuehl et al., 1975). Right ventricular (RV) cineangiocardiography was performed in all 7 patients in the right anterior oblique position. Quantitative analysis of the $\mathrm{LV}$ right anterior oblique cineangiograms was carried out according to the 'area-length' method (Dodge et al., 1966). End-diastolic and endsystolic volumes of the left ventricle were calculated in each patient and the $\mathrm{LV}$ ejection fraction was derived as the angiographic stroke volume divided by the end-diastolic volume $\times 100$. Mean velocity of circumferential fibre shortening $\left(\nabla_{C F}\right)$ was calculated from the extent of systolic shortening of the equatorial minor axis and the systolic ejection time (Karliner et al., 1971). Ejection time was determined from the aortic pressure tracing, but in 2 patients (cases 2 and 5 ) with severe mitral regur. gitation 'isovolumetric' contraction time was added to the conventional ejection time. The range of normality of the angiographic parameters was given by the results obtained in 34 patients without LV disease (Simon et al., 1974).

\section{SURGICAL TREATMENT}

Of the 7 patients with endomyocardial fibrosis, 4 (cases 2-5) were treated by decortication of the ventricular cavity and removal of one or both atrioventricular valves. In 3 patients (cases 2,4 , and 5) with mainly LV fibrosis and moderate to severe mitral regurgitation decortication of the left ventricle and mitral valve replacement were performed using Björk-Shiley prostheses in 2 instances and a Lillehei-Kaster prosthesis in the other (see Table 1). In 1 patient (case 3) with severe biventricular endomyocardial fibrosis both ventricles were decorticated and both atrioventricular valves were replaced by a Björk-Shiley prosthesis on the left and a porcine Hancock-prosthesis on the right side. Because the decortication of the right ventricle led to third degree atrioventricular block a permanent pacemaker had to be implanted. All patients who were operated on recovered well.

FOLLOW-UP

The clinical course was followed in our 7 patients for a mean observation time of 36 months (see Table 1). The 4 patients who were operated on were restudied by catheterisation and angiocardiography 4 to 14 months after operation.

Table 2 Pre-and postoperative haemodynamic data in 7 patients with endomyocardial fibrosis

\begin{tabular}{|c|c|c|c|c|c|}
\hline & & No. & Mean & $S D$ & Normal values \\
\hline HR (beats/min) & $\begin{array}{l}\text { Pre } \\
\text { Post }\end{array}$ & $\begin{array}{l}7 \\
4\end{array}$ & $\begin{array}{l}84 \\
79\end{array}$ & $\begin{array}{l}19 \\
24\end{array}$ & \\
\hline BSA $\left(\mathrm{m}^{2}\right)$ & $\begin{array}{l}\text { Pre } \\
\text { Post }\end{array}$ & $\begin{array}{l}7 \\
4\end{array}$ & $\begin{array}{l}1.57 \\
1.67\end{array}$ & $\begin{array}{r}0 \cdot 11 \\
0 \cdot 10\end{array}$ & \\
\hline RVEDP (mmHg) & $\begin{array}{l}\text { Pre } \\
\text { Post }\end{array}$ & $\begin{array}{l}4 \\
7 \\
4\end{array}$ & $\begin{array}{c}12.01 \\
8\end{array}$ & $\begin{array}{l}0.10 \\
6 \\
4\end{array}$ & $\leqslant 8$ \\
\hline LVEDP (mmHg) & $\begin{array}{l}\text { Pre } \\
\text { Post }\end{array}$ & $\begin{array}{l}7 \\
4\end{array}$ & $\begin{array}{l}25 \\
13 \star\end{array}$ & $\begin{array}{r}10 \\
4\end{array}$ & $\leqslant 14$ \\
\hline CI $\left(1 /\right.$ min per $\left.\mathrm{m}^{2}\right)$ & $\begin{array}{l}\text { Pre } \\
\text { Post }\end{array}$ & $\begin{array}{l}7 \\
4\end{array}$ & $\begin{array}{l}1.83 \\
2.48 \dagger\end{array}$ & $\begin{array}{l}0.29 \\
0.69\end{array}$ & $\geqslant 2.5$ \\
\hline RGF $_{M I}(\%)$ & $\begin{array}{l}\text { Pre } \\
\text { Post }\end{array}$ & $\begin{array}{l}7 \\
4\end{array}$ & 24 & $\begin{array}{r}22 \\
2\end{array}$ & - \\
\hline $\mathbf{E F}(\%)$ & $\begin{array}{l}\text { Pre } \\
\text { Post }\end{array}$ & $\begin{array}{l}7 \\
4\end{array}$ & $\begin{array}{l}61 \\
60\end{array}$ & $\begin{array}{r}8 \\
12\end{array}$ & $62-78$ \\
\hline $\operatorname{EDVI}\left(\mathrm{ml} / \mathrm{m}^{2}\right)$ & $\begin{array}{l}\text { Pre } \\
\text { Post }\end{array}$ & $\begin{array}{l}7 \\
4\end{array}$ & $\begin{array}{l}68 \\
84\end{array}$ & $\begin{array}{l}22 \\
24\end{array}$ & $59-121$ \\
\hline$\overline{\mathbf{V}}_{\mathrm{Cr}}(\operatorname{circ} / \mathrm{s})$ & $\begin{array}{l}\text { Pre } \\
\text { Post }\end{array}$ & $\begin{array}{l}7 \\
4\end{array}$ & $\begin{array}{l}1.26 \\
1.25\end{array}$ & $\begin{array}{l}0.38 \\
0.36\end{array}$ & $1 \cdot 0-2 \cdot 0$ \\
\hline $\mathrm{L} / \mathrm{M}$ & $\begin{array}{l}\text { Pre } \\
\text { Post }\end{array}$ & $\begin{array}{l}7 \\
4\end{array}$ & $\begin{array}{l}1 \cdot 21 \\
1 \cdot 14\end{array}$ & $\begin{array}{l}0.24 \\
0 \cdot 23\end{array}$ & $1 \cdot 6-2 \cdot 5$ \\
\hline
\end{tabular}

$\star P<0.05 ;+P<0.025$ (paired Student's $t$ test)

RV and LVEDP, right and left ventricular end-diastolic pressure; $C I$ cardiac index; RGF $\mathrm{MI}$, mitral regurgitation fraction; EF, left ventricular ejection fraction; EDVI, left ventricular end-diastolic volume index; $\overline{\mathbf{V}}_{\mathrm{CF}}$, mean velocity of circumferential fibre shortening; L/M, end-diastolic ratio between long $(\mathrm{L})$ and equatorial minor axis $(\mathrm{M})$ of left ventricle. 

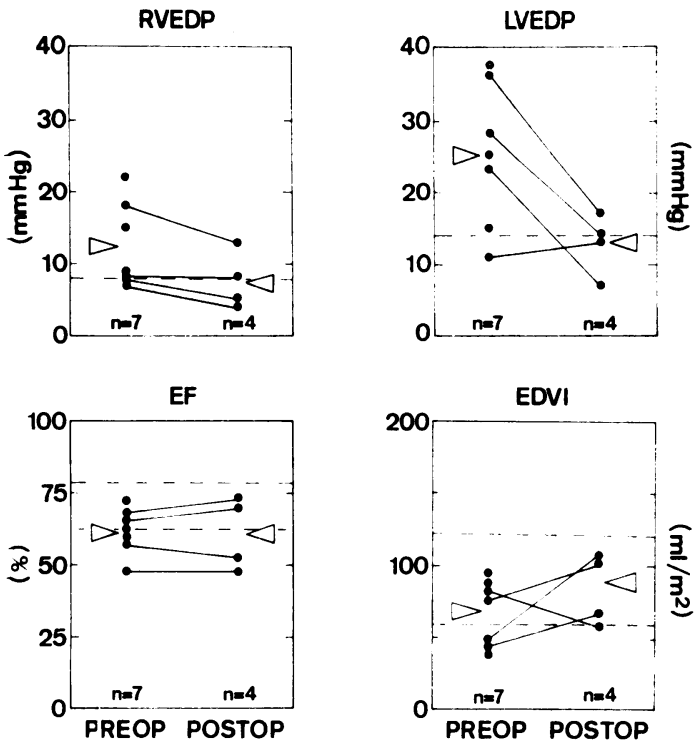

Fig. 1 Pre- and postoperative haemodynamic findings in patients with endomyocardial fibrosis. Right ventricular end-diastolic pressure (RVEDP) decreased from 12 to $8 \mathrm{mmHg}$ after surgery (not significant), but left ventricular end-diastolic pressure (LVEDP) showed a significant $(P<0.05)$ decrease from 25 to 13 $\mathrm{mmHg}$ because of the improved left ventricular distensibility after endocardial decortication. Left ventricular systolic ejection fraction (EF) remained unchanged after operation compared with the preoperative state. Left ventricular end-diastolic volume index (EDVI) increased in 3 patients after decortication of the left ventricle. One patient with incomplete decortication showed a decreased EDVI after operation. Dashed lines (RVEDP and LVEDP), upper limit of normal; dashed lines ( $E F$ and $E D V I)$, upper and lower limit of normal; triangle, mean value.

\section{Results}

\section{(1) HAEMODYNAMICS}

(a) Preoperative

LV end-diastolic pressure was raised to $25 \mathrm{mmHg}$ (Table 2, Fig. 1). In only 1 patient (case 5) was the LV end-diastolic pressure normal after intensive and prolonged diuretic therapy. RV end-diastolic pressure was raised to a mean of $12 \mathrm{mmHg}$, but in 3 patients (cases $1,4,7$ ) with severe fibrosis of the right ventricle the end-diastolic pressure was higher than $15 \mathrm{mmHg}$. In 2 patients (cases 2 and 5) with angiographically mild RV fibrosis the end-diastolic pressure did not differ from the end-diastolic pressure of the 2 patients (cases 3 and 6 ) with a normal right ventricle. The cardiac index was decreased to $1.8 \mathrm{l} / \mathrm{min}$ per $\mathrm{m}^{2}$. Mitral regurgitation was severe in 2 patients $(55 \%)$, moderate in $2(22 \%)$, and slight in 3 (about 5\%). Tricuspid regurgitation was slight in 4 patients and moderate in 1 patient. In addition, 1 patient (case 6) showed slight aortic regurgitation (about $5 \%$ ) with slight valvular and supravalvular stenosis (mean systolic pressure gradients $25 \mathrm{mmHg}$ and $8 \mathrm{mmHg}$, respectively). In another patient (case 5) with severe mitral regurgitation slight mitral stenosis was present (mean diastolic pressure gradient 6 $\mathrm{mmHg}$ ).

\section{(b) Postoperative}

LV end-diastolic pressure decreased significantly in 4 patients (cases 2 to 5 ) after decortication and valve replacement $(P<0.05)$ from 25 to $13 \mathrm{mmHg}$ and the RV end-diastolic pressure not significantly from 12 to $8 \mathrm{mmHg}$ (Table 1, Fig 1). In 1 patient (case 5) with normal LV end-diastolic pressure before operation caused by prolonged diuretic therapy, there was no change in end-diastolic pressure after operation. In 1 patient (case 2) minimal paravalvular mitral regurgitation was found after valve replacement, and in 2 patients (cases 2 and 5), who had surgery only of the left heart, mild tricuspid regurgitation was present caused by fibrosis of the right ventricle. One patient with biventricular decortication and valve replacement (case 3) showed a good functional result without atrioventricular regurgitation postoperatively. The cardiac index increased significantly $(\mathrm{P}<0.025)$ from 1.9 to $2.51 / \mathrm{min}$ per $\mathrm{m}^{2}$.

\section{(2) ANGIOCARDIOGRAPHY}

\section{(a) Preoperative}

Preoperatively all patients showed a small LV cavity with globular configuration (see Fig. 2, 5). The apex was obliterated and, therefore, the wall thickness was increased. The inner surface of the left ventricle was generally very smooth, but in 2 patients (cases 6 and 7) the obliteration of the apex appeared to be the result of irregular endocardial thickening. The overall LV contractions were in most cases well preserved, but in 3 patients the extent of contraction was slightly or moderately depressed. Of the 7 patients, 5 (cases $1,2,3,5,7$ ) showed not only endomyocardial fibrosis of the left ventricle, but also fibrosis of the right ventricle, with obliteration of the apex and the corpus. In 4 patients the right ventricle was extensively obliterated and formed a narrow tube, with one or two additional small cavities in the apical region (see Fig. 3, 5). The infundibulum of the right outflow tract was somewhat dilated and showed good 


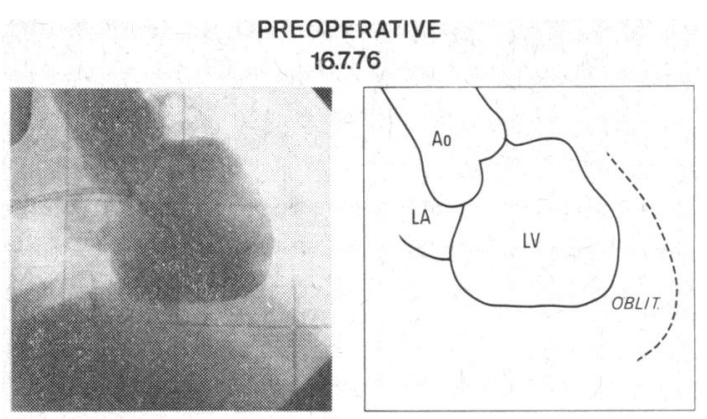

POSTOPERATIVE 1.2.77
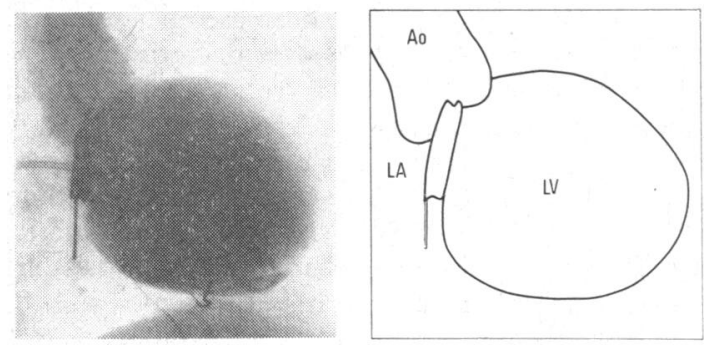

Fig. 2 Pre- and postoperative left ventricular cineangiograms at end-diastole (right anterior oblique position) in case 3 with biventricular endomyocardial fibrosis. The left ventricular cavity was small before operation with globular configuration. The apex was obliterated and the inner surface very smooth. Left ventricular volume was increased after endocardial decortication. However, the inner surface was still smooth and the ventricular cavity globular in shape. Ao, ascending aorta; $L V$, left ventricle; $L A$, left atrium; Oblit., obliteration of the apex.

contractions. One patient (case 7) with severe restriction to RV filling ( $R V$ end-diastolic pressure $22 \mathrm{mmHg}$ ) showed a more patchy endocardial thickening than the other 4 patients.

Quantitative assessment of $\mathrm{LV}$ function (see Fig. 1) disclosed adequate or good function. LV ejection fraction and mean circumferential fibre shortening velocity were normal in 4 and slightly decreased in 3 patients (see Table 2). LV enddiastolic volume index was small and the enddiastolic pressure-volume relation (Fig. 4) indicated greatly decreased distensibility of the left ventricle. In only 1 patient (case 5) was the end-diastolic pressure-volume relation within the range of normality. The end-diastolic ratio between the long (L) and the equatorial minor axis $(M)$ in all 7 patients showed (see Table 2) low values because of the globular configuration of the left ventricle.

RV function seemed to be normal or slightly reduced in patients with endomyocardial fibrosis.

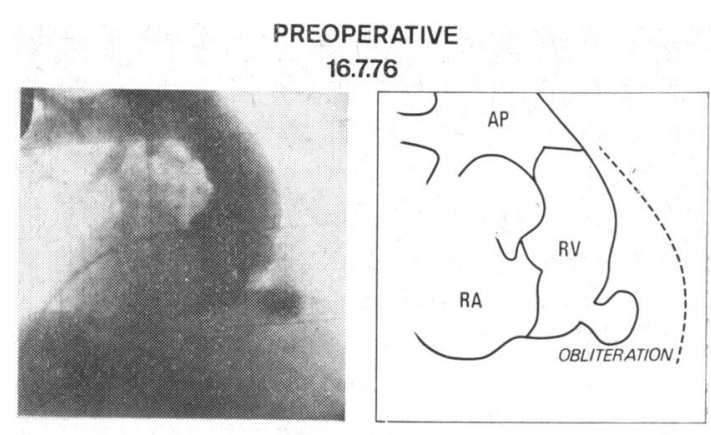

POSTOPERATIVE

1.2.77
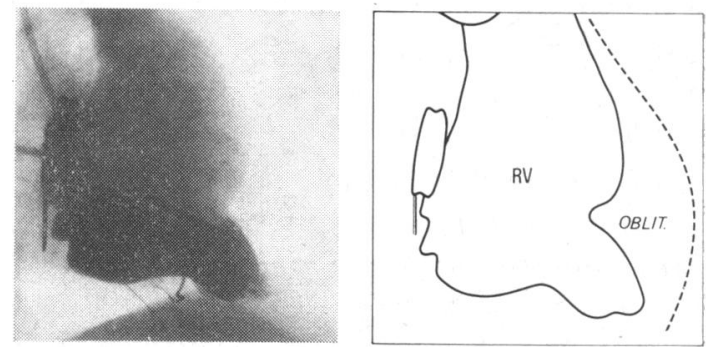

Fig. 3 Pre- and postoperative right ventricular cineangiograms (right anterior oblique position) at end-diastole in case 3 with biventricular endomyocardial fibrosis. The right ventricle was obliterated before operation and formed a narrow tube with one additional small cavity in the apical region. After right-sided endocardial decortication and tricuspid valve replacement the ventricular cavity was increased, but the additional apical cavity was still present and partial obliteration of the apex remained. AP, pulmonary artery; $R V$, right ventricle; $R A$, right atrium; Oblit., obliteration.

Usually, the corpus portion of the right ventricle showed decreased contractions and the infundibulum good contractions.

\section{(b) Postoperative}

$\mathrm{LV}$ end-diastolic volume index increased in 3 of the 4 operated patients. One patient, however, showed a $O$ decreased LV volume because of incomplete N decortication. The parameters of $\mathrm{LV}$ function $\underset{\mathrm{N}}{\mathrm{N}}$ $\left(E F, \bar{V}_{C F}\right)$ remained unchanged (see Table 2) compared with the preoperative state. The $L V_{0}$ end-diastolic pressure-volume relation (see Fig. 4) disclosed an increase in $\mathrm{LV}$ end-diastolic dis- $\stackrel{9}{+}$ tensibility in 3 patients. One patient with preoperative normal LV end-diastolic distensibility showed a slight decrease in LV distensibility after decortication (case 5).

In the patient in whom RV decortication was carried out the cavity size of the right ventricle increased postoperatively (Fig. 3). 


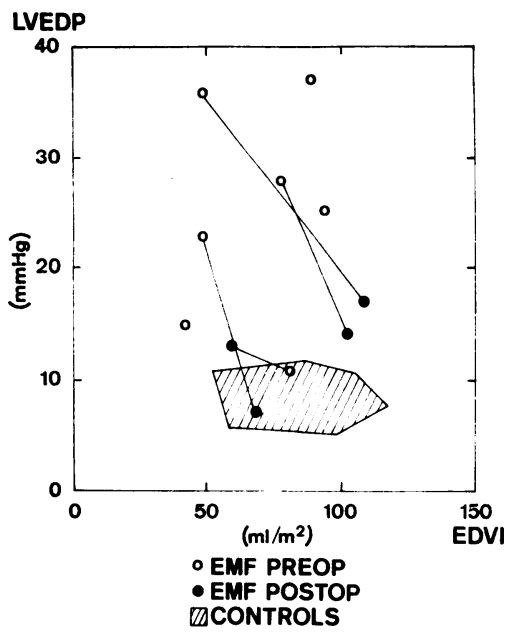

Fig. 4 Pre-and postoperative end-diastolic pressurevolume relation in 7 patients with endomyocardial fibrosis $(E M F)$. The preoperative pressure-volume relation (open circles) showed a sizeably decreased distensibility of the left ventricle in 6 of the 7 patients with EMF. In one patient the end-diastolic distensibility was within the range of normal after intensive and longstanding diuretic therapy. Postoperative pressurevolume relation (closed circles) revealed an increase in left ventricular end-diastolic distensibility in 3 patients. However, 1 patient (case 5) with preoperative normal distensibility showed a slight decrease in left ventricular distensibility after operation, probably because of incomplete endocardial decortication. LVEDP, left ventricular end-diastolic pressure; EDVI, left ventricular end-diastolic volume index; $E M F$ preop, preoperative patients with endomyocardial fibrosis; EMF postop, postoperative patients with endomyocardial fibrosis; Controls, 19 patients without left ventricular disease served as controls.

\section{(3) ECHOCARDIOGRAPHY}

Endocardial fibrosis of the posterior wall was found preoperatively in 4 of the 6 patients who were assessed echocardiographically. The interventricular septum (see Table 3) was of normal thickness and showed paradoxical motion in one patient only. The left atrium was enlarged in all 6 patients. Thickening of the RV anterior wall was found in 2 patients (cases 1 and 3) with angiographically severe fibrosis of the right ventricle, and systolic obliteration of the RV cavity was shown by angulation of the echocardiographic beam towards the RV apex (Fig. 6). A minor pericardial effusion was found in 3 of the 6 patients.

In 2 patients postoperative evaluation by echocardiography disclosed a diminution of fibrosis of the posterior wall and a slight increase in LV transverse diameter (Table 3). In 1 patient

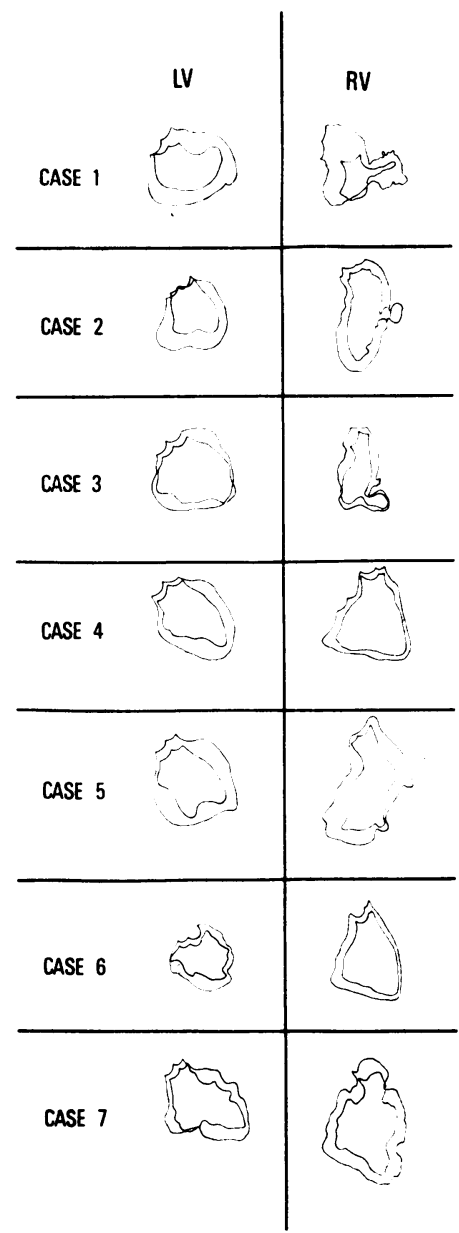

Fig. 5 Preoperative left and right ventricular enddiastolic and end-systolic cineangiograms (right anterior oblique position) in 7 patients with endomyocardial fibrosis. The left ventricle $(L V)$ shows a globular configuration in all 7 cases and contractions are good or slightly reduced. A more patchy endocardial fibrosis is seen in cases 6 and 7 than in the other 5 patients. The right ventricle $(R V)$ is involved by endomyocardial fibrosis in 5 patients (cases 1, 2, 3, 5, 7); in 4 the right ventricle is extensively obliterated and forms a narrow tube with one or two additional small cavities. Case 7 with severe restriction to filling shows a more patchy right ventricular endocardial thickening.

with decortication of both ventricles (Fig. 6) the preoperative systolic obliteration of the RV cavity was absent after operation and the RV diameter was increased.

\section{(4) HISTOLOGICAL FINDINGS}

The decorticated endocardium and the atrioventricular valves that were removed were examined 
Table 3 Pre-and postoperative echocardiographic data in 6 patients with endomyocardial fibrosis

\begin{tabular}{|c|c|c|c|c|c|c|c|}
\hline & & \multicolumn{3}{|c|}{ Endomyocardial fibrosis } & \multicolumn{3}{|c|}{ Normal values $\star$} \\
\hline & & No. & Mean & $S D$ & No. & Mean & $S D$ \\
\hline HR (beats/min) & $\begin{array}{l}\text { Pre } \\
\text { Post }\end{array}$ & $\begin{array}{l}6 \\
4\end{array}$ & $\begin{array}{l}74 \\
80\end{array}$ & $\begin{array}{l}23 \\
21\end{array}$ & 50 & 71 & 12 \\
\hline $\mathrm{LA}\left(\mathrm{cm} / \mathrm{m}^{2}\right)$ & $\begin{array}{l}\text { Pre } \\
\text { Post }\end{array}$ & $\begin{array}{l}6 \\
4\end{array}$ & $\begin{array}{l}2 \cdot 8 \\
2 \cdot 2 t\end{array}$ & $\begin{array}{l}0 \cdot 6 \\
0.4\end{array}$ & 50 & 1.5 & 0.3 \\
\hline $\mathrm{RV}\left(\mathrm{cm} / \mathrm{m}^{2}\right)$ & $\begin{array}{l}\text { Pre } \\
\text { Post }\end{array}$ & $\begin{array}{l}6 \\
4\end{array}$ & $\begin{array}{l}1.5 \\
1.1\end{array}$ & $\begin{array}{l}0.3 \\
0.3\end{array}$ & 50 & 0.9 & 0.5 \\
\hline $\operatorname{LV}\left(\mathrm{cm} / \mathrm{m}^{2}\right)$ & $\begin{array}{l}\text { Pre } \\
\text { Post }\end{array}$ & $\begin{array}{l}6 \\
4\end{array}$ & $\begin{array}{l}3 \cdot 1 \\
3 \cdot 2\end{array}$ & $\begin{array}{l}0.6 \\
0.2\end{array}$ & 50 & $2 \cdot 7$ & 0.8 \\
\hline SH (\%) & $\begin{array}{l}\text { Pre } \\
\text { Post }\end{array}$ & $\begin{array}{l}6 \\
4\end{array}$ & $\begin{array}{l}41 \\
37\end{array}$ & $\begin{array}{r}10 \\
5\end{array}$ & 50 & 33 & 3 \\
\hline IVS $_{\text {ed }}(\mathrm{cm})$ & $\begin{array}{l}\text { Pre } \\
\text { Post }\end{array}$ & $\begin{array}{l}6 \\
4\end{array}$ & $\begin{array}{l}1 \cdot 0 \\
1.0\end{array}$ & $\begin{array}{l}0 \cdot 1 \\
0 \cdot 1\end{array}$ & 50 & 0.9 & $0 \cdot 1$ \\
\hline PW ed (cm) & $\begin{array}{l}\text { Pre } \\
\text { Post }\end{array}$ & $\begin{array}{l}6 \\
4\end{array}$ & $\begin{array}{l}0.9 \\
0.9\end{array}$ & $\begin{array}{l}0 \cdot 1 \\
0.1\end{array}$ & 50 & 0.9 & $0 \cdot 1$ \\
\hline $\mathbf{V}_{\mathbf{C F}}(\operatorname{circ} / \mathrm{s})$ & $\begin{array}{l}\text { Pre } \\
\text { Post }\end{array}$ & $\begin{array}{l}6 \\
4\end{array}$ & $\begin{array}{l}1.5 \\
1.4\end{array}$ & $\begin{array}{l}0 \cdot 3 \\
0 \cdot 2\end{array}$ & 50 & $1 \cdot 3$ & 0.3 \\
\hline
\end{tabular}

*(Felner and Story, 1976); $+P<0.02$ (paired Student's $t$ test)

SH, per cent systolic shortening of left ventricular transverse diameter; IVS ed, end-diastolic thickness of interventricular septum; PW $_{\text {ed }}$ end-diastolic thickness of the posterior wall; for other abbreviations see Table 2.

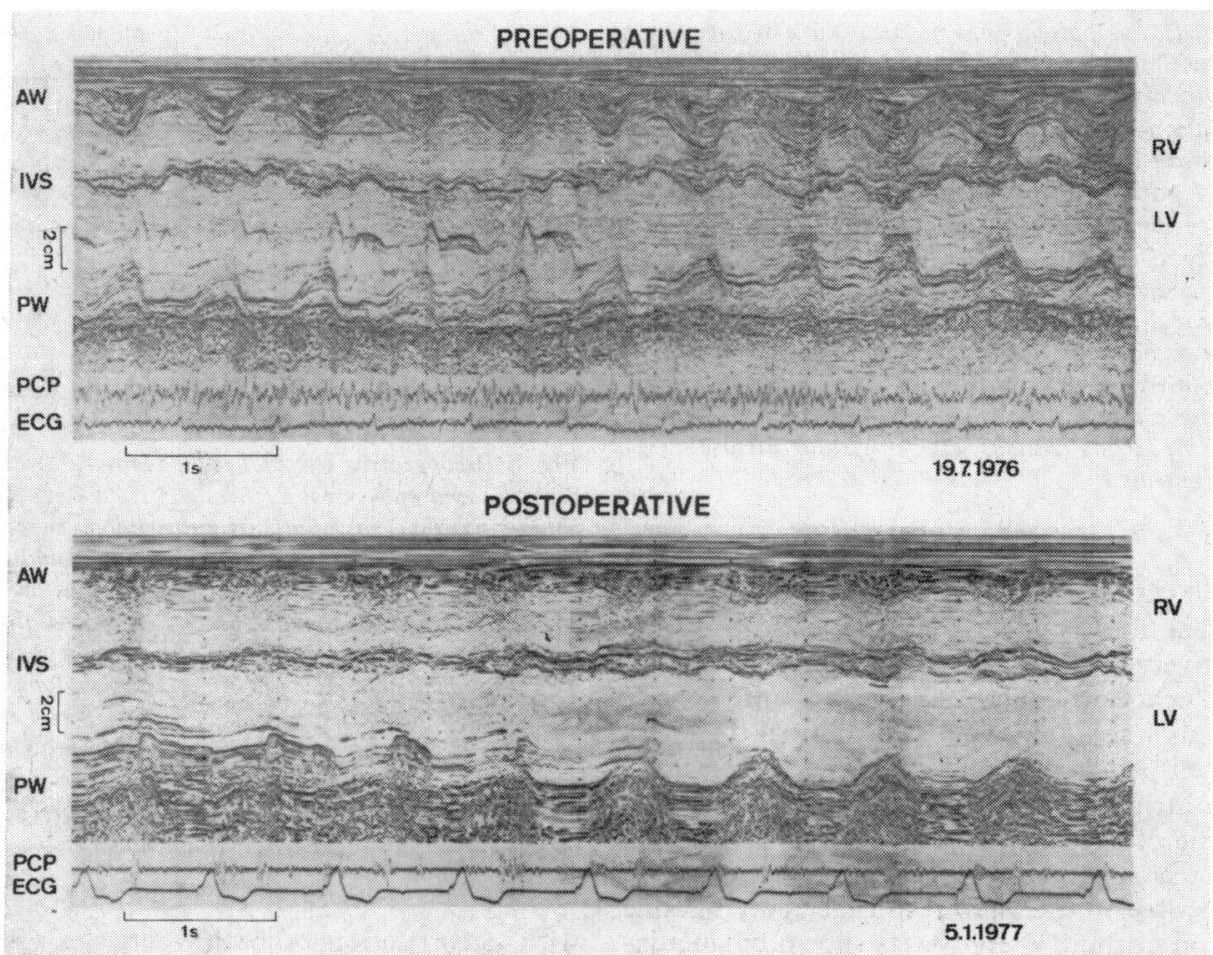

Fig. 6 Pre- and postoperative echocardiograms in case 3 with biventricular endomyocardial fibrosis. Endocardial thickening of the right ventricular anterior wall with systolic obliteration of the right ventricular cavity toward the apex is shown in the preoperative echocardiogram. Endocardial fibrosis of the left ventricular posterior wall is found toward the left ventricular apex. Postoperative assessment shows a diminution of the right anterior and left posterior endocardial thickening. The systolic obliteration of the right ventricular cavity seen before operation is absent after biventricular endocardial decortication and valve replacement. AW, anterior wall; IVS, interventricular septum; $P W$, posterior wall; $P C P$, phonocardiogram; $E C G$, electrocardiogram; $R V$, right ventricle; $L V$, left ventricle. 
histologically in all 4 operated patients. The histological findings were similar to those of Brockington and Olsen (1973): there was some hyalinised collagen tissue in a first layer and some fibrous tissue in a second layer with subendocardial calcification in 3 patients. Granulation tissue or inflammatory cells were not found.

In 3 cases the mitral valve showed the typical findings of endomyocardial fibrosis with a thin layer of fibrous tissue on an otherwise normal valve; in one case, however, there was a thickened, vascularised, and calcified valve caused by earlier mitral endocarditis.

(5) FOLLOW-UP

One medically treated patient with biventricular endomyocardial fibrosis (case 1) showed good functional improvement with diuretics and digitalis (NYHA III to II). This patient remained stable during the next 3 years. Another patient (case 7) had moderate to severe right heart failure during an observation period of 3 years (NYHA III) and remained more or less stable during this time. The third medically treated patient (case 6 ) suffered from progressive congestive heart failure and died 6 years later in a severe low-output state.

The clinical course of the 4 surgically treated patients 4 to 14 months after the operation showed good functional results: 3 patients progressed from functional class III to II and 1 patient with biventricular decortication and valve replacement progressed from class IV to III. In this group, no patient died.

\section{Discussion}

Endomyocardial fibrosis is a severe heart disease affecting young adults of both sexes. The disease is found in East- and South-Africa and has a poor prognosis. Treatment consists of diuretics and digitalis, but surgical treatment has recently been reported (Dubost et al., 1976). In the present study both ventricles were involved by the disease in 5 of the 7 patients. In the remaining 2 patients the fibrosis was confined to the left ventricle. The extent of diastolic restriction to filling and the degree of valve regurgitation varied considerably among the patients.

\section{DIAGNOSIS}

The diagnosis of endomyocardial fibrosis is made by angiocardiography (Cockshott, 1965), but it is possible to detect endocardial fibrotic lesions by echocardiography. A history of severe congestive heart failure, moderate enlargement of the heart on chest $x$-ray film, and small left and right ventricular cavities with well-preserved wall contractions and endocardial thickening in the echocardiogram allows the diagnosis of endomyocardial fibrosis to be made by noninvasive methods. Endomyocardial biopsy of the right and the left ventricle may be helpful in some patients (Somers et al., 1971).

\section{AETIOLOGY}

True aetiological factors were not found in our 7 patients with endomyocardial fibrosis; the only common finding was a history of chronic inflammation in 6 of the 7: acute rheumatic fever had occurred in 2 patients, and chronic pyelonephritis, osteoclastoma with inflammation of the elbow, Q-fever myocarditis, and pulmonary tuberculosis each in 1 patient. A causal connection between endomyocardial fibrosis and chronic inflammatory disease remains, however, speculative. The role of antimyocardial antibodies in endomyocardial fibrosis is unclear, but there is no convincing evidence that an autoimmune process causes fibrosis of the endomyocardium. Some authors related the incidence of endomyocardial fibrosis in South- and East-Africa to the increased consumption of plants rich in serotonin (Crawford, 1963); others suggested malnutrition, filiariasis, and viral disease (Shaper et al., 1968; McKinney, 1975) as aetiological factors, but there is no explanation as to why the occurrence of endomyocardial fibrosis is limited to South- and East-Africa. A striking difference between the endemic African and the sporadic European form of endomyocardial fibrosis is the predilection of women to have it in Europe.

\section{PATHOGENESIS}

The clinical course in endomyocardial fibrosis is determined by the location of the fibrotic lesions. Involvement of the right ventricle causes RV congestive failure, involvement of the left ventricle LV congestive failure. Fibrosis of the endomyocardium leads to an increased filling resistance of the ventricles and to dysfunction of the papillary muscles with atrioventricular valve regurgitation. If the fibrotic lesion involves predominantly the apical region of the heart, filling restriction is the main haemodynamic feature; if the fibrosis is mainly located to the inflow tract, atrioventricular valve regurgitation predominates. In our patients filling restriction was predominant in 3 and atrioventricular regurgitation was predominant in 2 . These distinct problems demand different surgical procedures: filling restriction should be treated by endocardial decortication of the fibrotic lesion, and atrioventricular valve regurgitation should be treated by valve replacement. 
TREATMENT

Medical treatment consists of digitalis and high doses of diuretics. Anticoagulants have to be used in patients with low-output syndrome or arrhythmias caused by atrial fibrillation. The surgical procedures are endocardial decortication of the ventricular cavity and atrioventricular valve replacement. Dubost and coworkers (1976) found good to excellent clinical improvement in 5 operated patients 2 to 56 months after the operation. One patient, however, died 20 months after the operation. In patients with severe filling restriction it is important to remove as much of the fibrotic endocardium as possible, because partial decortication is ineffective in improving ventricular filling as shown in case 5 (Fig. 4). Decortication includes the replacement of the atrioventricular valve, because the fibrosis usually involves the posterior papillary muscle and the chordae tendineae. Since systolic function of the myocardium is well preserved or only slightly reduced operation can be carried out with relatively low risk, though cardiac failure is severe in most patients ( 3 were in functional class III and one in class IV before operation).

\section{FOLLOW-UP}

The prognosis in patients with endomyocardial fibrosis is usually bad and medical treatment is often unsatisfactory. Decortication and valve replacement seem to offer a good alternative to medical treatment. The 4 patients who were operated on show good functional improvement after operation. Nine months later there was an increase of physical working capacity from 25 to 56 per cent (see Table 1). Re-evaluation of the 4 patients by cardiac catheterisation and angiocardiography showed a significant decrease in LV end-diastolic pressure and a significant increase in cardiac output. Systolic ejection fraction remained unchanged, but LV end-diastolic volume index increased in 3 patients following the removal of the filling obstruction by endocardial decortication. In the same patients the end-diastolic pressurevolume relation disclosed a decrease in ventricular stiffness, or in other words an increase in ventricular distensibility (Fig. 4). One patient (case 5) with normal end-diastolic distensibility of the left ventricle before operation showed a slight decrease in distensibility after operation.

\section{LÖFFLER'S ENDOCARDITIS}

The same angiographic picture as in endomyocardial fibrosis can be seen in Löffler's endocarditis (Bell et al., 1976; Chew et al., 1977). But in contrast to what has been reported in Löffler's endocarditis there was no eosinophilia, no embolisation, no fever, and no vasculitis in our patients. Histologically we found the typical alterations of endomyocardial fibrosis with subendocardial calcification in 3 patients. However, according to the work of Brockington and Olsen (1973) the fibrous stage of Löffler's endocarditis and endomyocardial fibrosis are indistinguishable on histological grounds.

In summary it can be said that endomyocardial fibrosis in Switzerland is a rare disease and is seen mainly in women. The clinical picture is dominated by severe congestive heart failure, but in the chest $x$-ray film the heart is only moderately enlarged. Angiocardiography shows a small left and right ventricular cavity with good contractions and typical endocardial thickening. Today endomyocardial fibrosis has become a surgical disease and endocardial decortication with atrioventricular valve replacement seems to be an adequate treatment, with good postoperative functional improvement.

\section{References}

Bell, J. A., Jenkins, B. S., and Webb-Peploe, M. M. (1976) Clinical, haemodynamic, and angiographic findings in Löffler's eosinophilic endocarditis. British Heart fournal, 38, 541-548.

Brockington, I. F., and Olsen, E. G. J. (1973). Löffler's endocarditis and Davies' endomyocardial fibrosis. American Heart fournal, 85, 308-322.

Chew, C. Y. C., Ziady, G. M., Raphael, M. J., Nellen, M., and Oakley, C. M. (1977). Primary restrictive cardiomyopathy. Nontropical endomyocardial fibrosis and hypereosinophilic heart disease. British Heart fournal, 39, 399-413.

Cockshott, W. P. (1965). Angiography of endomyocardial fibrosis. British fournal of Radiology, 38, 192-200.

Crawford, M. A. (1963). Endomyocardial fibrosis and carcinoidosis. A common denominatcr? American Heart fournal, 66, 273-275.

Davies, J. N. P. (1948). Endomyocardial necrosis. A heart disease of obscure aetiology in Africa. MD Thesis, Bristol.

Dodge, H. T., Sandler, H., Baxley, W. A., and Hawley, R. R. (1966). Usefulness and limitations of radiographic methods for determining left ventricular volume. American fournal of Cardiology, 18, 10-24.

Dubost, Ch., Maurice, P., Gerbaux, A., Bertrand, E., O Rulliere, R., Vial, F., Barillon, A., Prigent, C., Carpentier, A., and Soyer, R. (1976). The surgical treatment of constrictive fibrous endocarditis. Annals of Surgery, 184, 303-307.

Felner, J. M., and Story, W. E. (1976). Echocardiographic analysis of 50 normal individuals. In Echocardiography: a Teaching Atlas, pp. 519-523. Ed. by J. M. Felner and R. C. Schlant. Grune and Stratton, New York.

Karliner, J. S., Gault, D., Eckberg, D., Mullins, C. B., and Ross, J., Jr. (1971). Mean velocity of fiber shortening. A simplified measure of left ventricular myocardial contractility. Circulation, 44, 323-333.

Krayenbuehl, H. P., Schoenbeck, M., Rutishauser, W., and Wirz, P. (1975). Abnormal segmental contraction velocity in coronary artery disease produced by isometric exercise and atrial pacing. American fournal of Cardiology, 35, 785-794. 
Löffler, W. (1936). Endocarditis parietalis fibroplastica mit Bluteosinophilie (In German). Schweizerische medizinische Wochenschrift, 66, 817-820.

McKinney, B. (1975). Studies on the experimental production of endomyocardial fibrosis and cardiomegaly of unknown origin by dietary means. American Heart fournal, 90, 206-214.

Shaper, A. G., Hutt, M. S. R., and Coles, R. M. (1968). Necropsy study of endomyocardial fibrosis and rheumatic heart disease in Uganda 1960-1965. British Heart fournal, 30, 391-401.

Simon, R., Krayenbuehl, H. P., Rutishauser, W., Steiger, U., Brunner, H. H., and Schoenbeck, M. (1974). Evaluation of contraction performance in the normal human left ventricle (abstract). European fournal of Clinical Investigation, 4, 358-359.

Somers, K., Hutt, M. S. R., Patel, A. K., and D'Arbela, P. G. (1971). Endomyocardial biopsy in diagnosis of cardiomyopathies. British Heart fournal, 33, 822-832.

Requests for reprints to Dr O. M. Hess, Department of Internal Medicine, Medical Policlinic, Cardiology, Rämistrasse 100, 8091 Zurich, Switzerland. 